\title{
Importance of examination under anaesthesia in adolescent age group for effective diagnosis and treatment in diagnostic dilemma: case series
}

\author{
Shuchi Agarwal, Vandana Solanki*, Urmila Singh, Seema Mehrotra
}

Department of Obstetrics and Gynecology, King Georges Medical University, Lucknow, Uttar Pradesh, India

Received: 04 March 2019

Accepted: 02 April 2019

\section{*Correspondence:}

Dr. Vandana Solanki,

E-mail: solanki.vandana@gmail.com

Copyright: (c) the author(s), publisher and licensee Medip Academy. This is an open-access article distributed under the terms of the Creative Commons Attribution Non-Commercial License, which permits unrestricted non-commercial use, distribution, and reproduction in any medium, provided the original work is properly cited.

\begin{abstract}
Problems of the adolescent girls like discharge and bleeding per vaginum (BPV) are usually underestimated and under diagnosed and are considered as physiological. Often diagnosis not settled due to incomplete or absent examination. In such situations Examination under anaesthesia (EUA) is an invaluable method in the lower genital tract assessment of adolescent females. The aim of this study was to discuss Importance of EUA in adolescent age group with persistent complain of discharge and bleeding for aiding the diagnosis. Present case series discusses three cases of girls of adolescent age group who presented to tertiary care centre of Northern India over a period of six month with complain of discharge per vaginum and on and off bleeding $\mathrm{p} / \mathrm{v}$ which was refractory to medical management. After initial examination and investigations they were planned for Examination under Anaesthesia. Gynecological complaints such as vaginal discharge, irregular BPV are common complains in adolescent age group. Many complaints can be dealt with by reassurance, whereas most others respond to medical therapy. To facilitate diagnosis in recurrent or unresponsive patients EUA is recommended. In diagnostic dilemma and in unusual presentation in young age EUA is invaluable.
\end{abstract}

Keywords: Bleeding per vaginum, Examination under anaesthesia

\section{INTRODUCTION}

Gynecological complaints such as vaginal discharge and irregular BPV are common in young girls. Treating gynaecologist needs to have adequate knowledge about physiological changes and pathologies that affect these young girls so as to provide comprehensive health care. Many complaints can be dealt with by reassurance and medical treatment but in recurrent or unresponsive patients, an EUA is recommended as absent or incomplete examination may lead to delay in diagnosis or wrong diagnosis. ${ }^{1}$

These young girls and their parents need kind, gentle approach, counselling and reassurance from treating gynaecologist so as to allay anxiety of both.
Genital examination should be a routine part of a comprehensive physical examination for any girl at any age. Examination under anaesthesia (EUA) is an invaluable method in the lower genital tract assessment of adolescent females. Performing genital examination is challenging for both physician and young girl. It can lead to anxiety in both young girl and their parents they may consider it as breech in their privacy so any such examination should be preceded by thorough counselling of both patient and their parent and proper consent should be taken.

Patient and parents should be explained that examination will be done under anaesthesia ensuring privacy as doctor will be able to examine the patient more thoroughly without hurting while patient is asleep in anaesthesia. The 
examination will depend on where suspected pathology is and may include: examination of vulva, speculum will be used to examine the cervix. Manual examination by inserting a finger into vagina and rectum will be done.
Biopsy will be taken if required and will be sent for histopathological examination. During EUA cystoscopy and/or a hysteroscopy might be done if required.

Table 1: Case series.

\begin{tabular}{|c|c|c|c|}
\hline Case & Clinical symptoms & EUA findings & Management \\
\hline $\begin{array}{l}\text { Case } 1 \\
15 \text { yr girl }\end{array}$ & $\begin{array}{l}\text { Discharge per vaginum, } \\
\text { irregular BPV and pain in } \\
\text { abdomen for last } 3 \text { years } \\
\text { which was refractory to } \\
\text { medications }\end{array}$ & $\begin{array}{l}\text { Vagina filled with necrotic } \\
\text { friable growth of } 5 \times 6 \mathrm{~cm} \\
\text { arising from infra-vaginal part } \\
\text { of post lip of cervix-necrotic } \\
\text { growth removed and tissue sent } \\
\text { for biopsy }\end{array}$ & $\begin{array}{l}\text { HPE: Embryonal } \\
\text { Rhabdomyosarcoma (botyroid } \\
\text { variant } \\
\text { Patient was transferred to } \\
\text { pediatric oncology and } \\
\text { received IRS-IV protocol neo- } \\
\text { adjuvant chemotherapy }\end{array}$ \\
\hline $\begin{array}{l}\text { Case } 2 \\
15 \text { yr girl }\end{array}$ & $\begin{array}{l}\text { Presented with complains of } \\
\text { on and off BPV since } 9 \\
\text { months }\end{array}$ & $\begin{array}{l}\text { Large friable mass } 10 \times 8 \mathrm{~cm} \\
\text { occupying whole of vagina, seems } \\
\text { to be attached to the lower part of } \\
\text { cervix. Biopsy taken }\end{array}$ & $\begin{array}{l}\text { HPE- serous papillary adeno } \\
\text { carcinoma. } \\
\text { Six cycles of chemotherapy }\end{array}$ \\
\hline $\begin{array}{l}\text { Case } 3 \\
15 \text { yr girl }\end{array}$ & $\begin{array}{l}\text { Presented with complain of } \\
\text { discharge per vaginum and } \\
\text { some fleshy mass coming out } \\
\text { of vagina since last } 6 \text { month }\end{array}$ & $\begin{array}{l}\text { A toungue shaped fleshy mass } \\
\text { appox } 7 * 8 \mathrm{~cm} \text { seen arising from } \\
\text { post lip of cervix- growth } \\
\text { removed and tissue sent for } \\
\text { biopsy }\end{array}$ & $\begin{array}{l}\text { HPE: Endocervical polyp } \\
\text { Treatment: Excised }\end{array}$ \\
\hline
\end{tabular}

\section{CASE REPORT}

The retrospective review of three patients medical records that underwent EUA.

\section{Case 1}

A 15 years old girl presented with complaint of discharge per vaginum, irregular BPV and pain in abdomen for last 3 years which was refractory to medications prescribed from private hospitals, she came to our hospital in June 2016.

\section{On examination}

No cervical, axillary or inguinal lymphadenopathy found and no organomegaly Per Abdomen examinationSuprapubic mass: 14-16 weeks size felt, irregular margin, restricted mobility, non-tender, lower pole not reached.

\section{Local examination}

Dirty blood mixed discharge seems to be coming through vagina. Per-rectal examination: irregular mass of around 7x $6 \mathrm{~cm}$ felt to be arising from cervix, rectal mucosa free, $\mathrm{b} / \mathrm{l}$ parametrium free. She was advised USG and preoperative investigations and she was planned for EUA.USG- 13/6/16 Showed bulky uterus with large heterogeneously enhancing SOL in lower uterine segment involving cervix. EUA was done on 30/6/16 and we found vagina was filled with necrotic friable growth of $5 \times 6 \mathrm{~cm}$ arising from infra-vaginal part of post lip of cervix. Necrotic growth removed and tissue sent for biopsy.

\section{HPE}

Embryonal Rhabdomyosarcoma (botyroid variant). CT Scan 11.7.16- enlarged uterus with ill defined in homogeneously enhancing soft tissue lesion with multiple necrotic areas of around 9x8 cm in lower uterine segment abutting base of urinary bladder and bowel loops. No metastasis seen in any other organ.

Patient was transferred to pediatric oncology on 10.8.16 and received IRS-IV protocol neo-adjuvant chemotherapy. Referred back to us again with complain of discharge per vaginum again EUA done on 18.8.16friable growth $7 \times 6 \mathrm{~cm}$ seen arising from cervicovaginal junction-removed. Patient received chemotherapy from 29/10/16-11.5.17 consisting of induction comprising of Vincristine, Ifosamide, Mesna and Etoposide followed by chemotherapy as per IRS-IV Protocol.

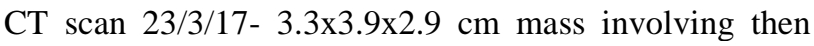
Cervical region and upper part of vagina. Patient referred from Pediatric oncology for evaluation before further maintenance chemotherapy; Underwent EUA on 8/6/17; $1.5 \mathrm{~cm} \times 1.5 \mathrm{~cm} \times 1 \mathrm{~cm}$ growth seen arising from posterior lip of cervix which was removed and HPE showed: Rhabdomyosarcoma with osteosarcoma differentiation Patient has received 28 cycle of chemotherapy till now and planned for further radiotherapy $\rightarrow$ CT Scan on 9/8/17- showed $2.9 \times 3.5 \times 2.7 \mathrm{~cm}$ mass. O/E done in OPD 
- Per Abdomen: Soft, non-tender, no suprapubic mass felt; Local Examination: No discharge; P/S-no mass. Now patient is relieved and is under follow-up

\section{Case 2}

A 15 years old girl presented on 27th February 2017 with complain of on and off bleeding per vaginum for 9 months. She attained menarche at 14 years. On examination abdomen was soft, external genitalia were normal, on per rectal examination -hard mass felt uterus not felt separately from mass. EUA done on 23/3/17 large friable mass $10 \times 8 \mathrm{~cm}$ occupying whole of vagina, seems to be attached to the lower part of cervix. Biopsy was taken from growth. Her CA125 was $87 \mathrm{u} / \mathrm{ml}$, CT scan showed large well defined heterogeneous enhanced soft tissue lesion $9 \times 7 \mathrm{~cm}$ in vagina infiltrating the vaginal walls with mild fat plane stranding. The lesion was having ill defined interface with cervix. The lesion was also causing compression and anterior displacement of urinary bladder with maintained fat planes. The lesion was also seen infiltrating adjacent anterior wall of rectum, ovaries were normal no free fluid no significant lymphadenopathy was seen.

On 26/2/17 CT Scan showed moderate to large size well defined lesion surrounding cervix and lower uterine body, 96*76 mm extending to posterior and lateral fornix, perileisonal planes maintained, rest uterus normal, no focal lesion in myometrium,uterine cavity was empty, both ovaries normal.CA125 was. $28.6 \mathrm{u} / \mathrm{ml}$ Cervical biopsy, 2.5.17 - showed serous papillary adeno carcinoma. Immuno histochemistry report-CA125Positive in tumor cells, P53-Focal positive in tumor cells. Patient received six cycles of chemotherapy, CarboplatinPaclitaxel.

\section{Case 3}

A case of missed undiagnosed cervical polyp history: 16 years old girl came with the chief complaint of discharge per vaginum and some fleshy mass coming out of vagina since last 6 month for which she did not seek any advice or treatment because of fear and anxiety of having caught some dreadful disease and came for the first time to our hospital on 17.8.18 Here at our side: General physical examination within normal limit, no cervical, axillary or inguinal lymphadenopathy found and no organomegaly, per Abdomen-soft, Local examination: A $4 \times 3 \mathrm{~cm}$ tongue shaped mass seen coming outside the introitus, Per-rectal examination: Uterus appeared normal in size, rectal mucosa free, $b / 1$ parametrium were free.

\section{Management}

Patient was advised USG and pre-operative investigations as she was planned for EUA. USG- 13/8/17 showed normal size uterus with $\mathrm{b} / \mathrm{l}$ normal ovaries with wellcircumscribed hypoechoeic mass within the endocervical canal. EUA done on $30 / 6 / 16 \rightarrow$ A toungue shaped fleshy massappox $7 * 8 \mathrm{~cm}$ seen arising from post lip of cervixgrowth removed and tissue sent for biopsy. HPE: showed mixed epithelium, squamous and endocervical type (with eosinophilic mucin). Endocervical epithelium with small, round and basal nuclei, Polypoid shape.+ Inflammation.Squamous metaplasia, No mitosis, no nuclear atypia, no stromal proliferation.

\section{DISCUSSION}

Cervical Rhabdomyosarcoma is a rare tumor occurring in young females and should be included in the differential diagnosis of a patient presenting with recurrent vaginal discharge refractory to treatment in this age group and proper clinical examination including per abdomen and per-rectal examination should be done. Rhabdomyosarcoma is a highly malignant soft tissue sarcoma arising from embryonal mesenchyma. It has been the most common soft tissue sarcoma in childhood, accounting for about 3 to $4 \%$ of all cases of childhood cancer. $^{2}$ The primary site of these tumors is closely related to the age of the patient; it is found in the vagina during infancy and early childhood, in the cervix during the active reproductive stage and in the corpus uteri for postmenopausal patients. Although vaginal tumors are five times more common than the cervical type, the latter appears to have a better prognosis than the former.

Rhabdomyosarcoma has been classified into three major histological types by IRMS study group embryonal, alveolar and undifferentiated. $0.5 \%$ of primary RMS in girls is found in cervix. Differential diagnosis includes benign conditions like rhabdomyoma, pseudosarcomabotryoides and malignant conditions like adenosarcoma.

Use of multidrug chemotherapy regimen as adjuvant to surgery has improved the overall prognosis in several trials. IRSG states that fertility sparing surgery followed by chemotherapy is the appropriate treatment for local control. The prognostic factors are histological type (embryonal botryoid having favorable outcome than alveolar subtype), metastatic disease at presentation and poor response to chemotherapy. ${ }^{3,4}$ The extent of the disease following primary surgical procedure is the most important prognostic factor. An early diagnosis is important as it favors a good prognosis. Surgery and chemotherapy is the mainstay of treatment with multimodality treatment. ${ }^{5}$ In present case report with early diagnosis and chemotherapy patient is doing well and is under regular follow up.

Case 2, currently, adenocarcinoma accounts for $10-25 \%$ of cases of invasive cervical cancer. The average age at presentation is in the 45-55 year range, but it is not uncommon to see adenocarcinoma in situ and invasive adenocarcinoma in younger women. ${ }^{6}$ The clinical presentation can be with an abnormal Pap smear, especially in patients with adenocarcinoma in situ and microinvasive adenocarcinoma, but most patients have 
abnormal bleeding. About $2 / 3$ of patients have stage I tumors at diagnosis and most of the rest have stage II tumors. Only $8-9 \%$ of women have stage III or IV adenocarcinomas at presentation. Survival is $70-80 \%$ in stage I and $32-37 \%$ in stage II. ${ }^{7}$ Staging of cervical cancer is based on clinical parameter Treatment has been the same as for other types of cervical carcinoma. In the largest series 6 of 15 patients died of carcinoma, an outcome similar to that observed in adenocarcinoma of the cervix overall. ${ }^{8}$ Serous carcinoma is a rare type of endocervical adenocarcinoma, occurs much less frequently than serous carcinoma of the endometrium. ${ }^{9}$ Only one series with a significant number of patients has been reported and it contained only 17 cases. $^{8}$ In one study, serous carcinoma did not appear to be associated with HPV infection. ${ }^{10}$

Most patients have visible tumors but a few stage Ia tumors have been reported. The gross appearance is similar to that of other types of cervical carcinoma. An exophytic pattern of growth is reported to be most common. Microscopically, the appearance is similar to serous carcinoma of the endometrium. The tumor grows in a papillary or glandular pattern with a variable amount of solid growth. The tumor cells are low columnar with large hyperchromatic nuclei. Nucleoli are variable, but can be large and conspicuous. Mitotic figures are numerous and there are generally more than 10/10 HPF. Psammoma bodies may be present. Lymphovascular space invasion is frequently identified. Serous carcinoma can occur as a pure type or a second type of cervical adenocarcinoma can be admixed. This can be villoglandular adenocarcinoma, and the villoglandular pattern can predominate. Tumors with a villoglandular component are most likely to occur in young patients.

Immunohistochemical studies of serous carcinoma of the cervix are limited. It appears to show positive staining for p53, like serous carcinomas elsewhere in the female genital tract, but in contrast with other types of cervical adenocarcinoma, it is unlikely to stain for CEA. ${ }^{11}$ Since serous carcinoma of the endometrium is much more common than serous carcinoma of the cervix, endocervical spread of an endometrial serous carcinoma must be excluded before a diagnosis of serous carcinoma of the cervix is made. The present case report is rare case report of serous papillary adenocarcinoma in 15 year old girl.

Case 3, A proper diagnosis of cervical polyps is very important. Not all polyps are benign and they may indicate a more serious problem, such as sexually transmitted diseases and cancers. Misdiagnosis of cervical polyps can occur under a variety of conditions such as polyps being mistaken for other diseases. Often, polyps are misdiagnosed as being uterine cancer, or cervical cancer. Polyps are sometimes simply missed entirely for lengthy periods of time. A cancer misdiagnosis is a serious problem as the treatment itself may lead to serious problems for the patient's health.
Conversely, misdiagnosing the polyps as benign can lead to a cancer that is left untreated for too long. In present case young women presented with mass coming out of vagina and discharge for which she got apprehensive of having some cancer so after proper diagnosis and histopathological confirmation that it is a benign polyp patient and her parents were relieved of the anxiety.

\section{CONCLUSION}

EUA is a safe and highly useful method in the assessment of the lower genital tract in adolescent girls in diagnostic dilemma.

\section{Funding: No funding sources \\ Conflict of interest: None declared \\ Ethical approval: Not required}

\section{REFERENCES}

1. Nakhal RS, Wood D, Creighton SM. The role of examination under anesthesia (EUA) and vaginoscopy in pediatric and adolescent gynecology: a retrospective review. J Pediatr Adolesc Gynecol. 2012;25(1):64-6.

2. Viella. Rhabdomyosarcoma of the cervix in sisters with review of the literature. Gynaecol Oncol. 2005;99:742-8.

3. Zrara I. Botryoid sarcoma of the uterine cervix. Gynecologie Obstetrique Fertilite. 2002;30:784-6.

4. Kayton ML, Wexler LH. Pediatric radical abdominal trachelectomy for anaplastic embryonal rhabdomyosarcoma of the uterine cervix; an alternative to radical hysterectomy. J Pediatr Surg. 2009;44:862-7.

5. Gilks CB, Clement PB. Papillary serous adenocarcinoma of the uterine cervix: a report of three cases. Modern Pathology. 1992;5:426-31.

6. Zhou C, Gilks CB. Papillary serous carcinoma of the uterine cervix - A clinicopathologic study of 17 cases. American Journal of Surgical Pathology. 1998;22(1):113-20.

7. Baalbergen A, Ewing-Graham PC, Hop WC, Struijk $\mathrm{P}$, Helmerhorst TJ. Prognostic factors in adenocarcinoma of the uterine cervix. Gynecol Oncol. 2004;92(1):262-7.

8. Chen Z, Blake GC, Malcolm H, Clement PB. Next Papillary Serous Carcinoma of the Uterine Cervix: A Clinicopathologic Study of 17 Cases. The American Journal of Surgical Pathology. 1998;22(1):113-20.

9. Gilks CB, Clement PB, Gilks CB, Clement PB. Modern Pathology. An Official Journal of the United States and Canadian Academy of Pathology. 1992;5(4):426-31.

10. Pirog EC, Semra BK, Bobkiewicz OP. Prevalence of Human Papillomavirus DNA in Different Histological Subtypes of Cervical Adenocarcinoma he. American Journal of Pathology. 2000;157(4):1055-62. 
11. Nofech-Mozes S, Rasty G, Ismiil N, Covens A, Khalifa MA. Immuno histochemical characterization of endocervical papillary serous carcinoma. Int $\mathbf{J}$ Gynecol Cancer. 2006;16(Suppl. 1):286-92.
Cite this article as: Agarwal S, Solanki V, Singh U, Mehrotra S: Importance of examination under anaesthesia in adolescent age group for effective diagnosis and treatment in diagnostic dilemma: case series. Int J Reprod Contracept Obstet Gynecol 2019;8:2133-7. 